\title{
FIFTH CONFERENCE ON PLANT BREEDING
}

\author{
ABSTRACTS of Papers read at the FIFTH CONFERENCE ON PLANT \\ BREEDING held at BAYFORDBURY on 24th-26th JULY 1952 under \\ the auspices of the AGRICULTURAL RESEARCH COUNCIL
}

\section{AIMS AND METHODS IN PLANT BREEDING \\ D. LEWIS \\ John Innes Horticultural Institution, Bayfordbury}

Aims in plant breeding depend upon several factors-the type of crop, the climate and soil in which it is grown, prevalence of disease, etc.-but one obvious factor in deciding what characters to concentrate upon is the past breeding history of the species.

Handsome returns to the breeders' work will be obtained with most characters in (I) natural species which have not been cultivated and therefore have not been selected either consciously by the breeder or unconsciously by the ancient husbandman. (2) Well-bred and cultivated species in an environment outside the range of their past cultivation. (3) In cultivated species which have been maintained as vegetatively reproduced clones in which seed production is rare. These three classes of species can be improved by breeding without much regard to careful discrimination of objectives. They require no further consideration here.

With highly bred species the situation is very different. A profitable return will only come from concentrating on virgin characters, i.e. characters which have not received attention in the past. Such characters are likely to be those which have been beyond the means of the unorganised breeding and unconscious selection of the past centuries-disease resistance, processing qualities, and phenotypic stability, i.e. the ability to reach a norm of phenotypic expression in a wide range of environments.

Breeding for disease resistance, processing qualities, etc. often require new techniques, and the success of such work largely depends upon rapid and efficient methods of assay. For example testing disease resistance on small seedlings and the analysis of sugar beet for sugar and noxious nitrogen on small amounts of material.

The ability to attain a phenotypic norm under widely different conditions, is a character the testing of which may require several different localities. Controlled environment chambers are a great help for detailed analysis of the genetic and physiological factors involved and also for a reproducable testing sieve for the plants.

I have been studying the interaction between genotype and environment for the last four years using the tomato as the test plant and the number of flowers in the inflorescence as the character. Temperature during the first 20 days of seedling growth was the environment studied. Preliminary experiments in 1949 and 1950 and the final experiment in 1952 all show that different parental pure lines show different degrees of phenotypic stability. The $F_{1}$ hybrid is much more stable than either of the parents and the stability in the $F_{3}$ generations ranges from that of the highly stable $F_{1}$ to that of the least stable parent. This clearly demonstrates that phenotypic stability is under genetic control and therefore will respond to selection.

A similar greater stability of the $\mathrm{F}_{1}$ hybrid was described in Potentilla glandulosa under mountain and coastal climates by Clausen at the International Genetics Congress in 1948. Mather (1950) found in Primula sinensis that the $F_{1}$ was less variable not only between plants but also within plants than the pure line parents. Haskell (1952), comparing pure lines and $F_{1}$ hybrids in maize for four characters found that hybrids varied less than pure lines under unsuitable environments. 
How general is this stability of $F_{1}$ hybrids only future work will tell, but if it is general then the economics of $F_{1}$ hybrid seed production in a number of cultivated plants should be reconsidered. For, the optimal size in many crop plants is already below the maximum attainable, and the hybrid vigour of $F_{1}$ 's would be of little advantage. But greater stability and reliability of performance in different localities and in different years is a factor of prime importance and warrants an all-out drive to breed $F_{1}$ hybrid seed, which can be produced cheaply. To do this emasculation of the mother parent must be genetic and not manual. Male sterility has been used in onions and tomatoes. Since male sterility is usually controlled by a recessive gene and is a defective character it is highly probable that X-rays would be effective in producing it in species where it is not already at hand.

Genetic emasculation can also be devised on a basis of self-incompatibility but it is necessary to know whether the Nicotiana-CEnothera or the Crepis-Parthenium systems are at work. The choice of emasculation method, whether it is male sterility - genic or cytoplasmic - or incompatibility will depend upon such factors as the ease of vegetative propagation and whether the reproductive or vegetative part of the plant is the commercial product. With all the available methods it seems possible to produce cheap hybrid seed in most crops except those which are irretrievably cleistogamous. The great advance in maize production by the use of $F_{1}$ hybrids in the U.S.A. should serve as a confident background to a much wider application of the method.

\section{REFERENCES}

Clausen, J. 1948. Genetics of climatic races of Potentilla glandulosa. P. Int. Gen. C. (8), pp. 162-1 72 .

hASKELI, G. 1952. Heterosis and adaptability. P. Int. Hort. C. (I3).

Mather, K. I950. The genetical architecture of heterostyly in Primula sinensis. Evolution, 4, 340-352.

\section{REPRODUCTION OF IMPROVED STOCKS}

\section{F. R. HORNE}

\section{Notional Institute of Agricultural Botony, Cambridge}

The breeding and scientific assessment of improved types in relation to agroecological conditions can only lead to increases in food production in so far as the seed stocks offered to the grower reproduce the essential characteristics of the type. (Gregor and Horne, r 1935). Strenuous efforts have been made by many commercial seedsmen and specialists but results of surveys of seed stocks often prove disappointing (North and Squibbs).

1. Confusion of identity is frequent in populations such as Wild White Clover and named types of brussels sprout which are distinguished mainly by quantitative characters. It appears to be more frequent in types known by numbers easily confused with other numbers such as S.23, Diamond II, Hybrid 29, Squareheads II. Some particularly valuable stocks, while they are in short supply, have shown a higher proportion of confused stocks and this is a class in which a high measure of authenticity is most desirable (Hawkins, 1951).

2. Synonyms constituted 75 per cent. of the names given to potato varieties until these were identified and classified by the National Institute of Agricultural Botany (N.I.A.B.). Recent work by North has shown that 70 per cent. of french bean varieties are synonyms. Under such conditions the grower may buy a variety as a novelty which is already known, under an older name, to be unsuited to his conditions.

3. The opposite position is also found among commercial seed stocks in that the same name may be given, as in Eldorado french bean and some strains of sugar beet, to two different and unrelated stocks.

4. Deterioration of stocks through genetic variation occurs most rapidly in types which are normally cross-fertilised. In surveys of Cambridge No. I brussels sprout 
6o per cent. of commercial seed stocks differed from the certified stock in varietal purity by more than Io per cent., while of 66 stocks 9 were no longer recognisable as containing plants of the named type ( $c f$. H.M. Stationery Office : Report on Seeds).

Through the co-operation of progressive seed growers, with the plant breeding stations and the N.I.A.B., seed certification schemes have been developed on a voluntary basis. These schemes aim at the preservation of varietal purity at a high level and the exclusion of seed-borne diseases and pernicious weed seeds.

Various schemes have been developed which are based on some or all of the following 5 principles :-

(I) Use of proved stock seed only. Sowings have shown that this is the most important principle and the development of vegetative propagation is proving a substantial aid to stock seed production.

(2) Inspection and approval of the field before the seed crop is sown to ensure freedom from "Volunteer" plants derived from earlier cropping.

(3) Inspection and approval of the growing seed crop at critical stages in growth for genetic purity, isolation from other types which might interpollinate, and freedom from seed-borne diseases and pernicious weeds.

(4) Sampling and sealing of the finally cleaned produce.

(5) Growing the samples of seed stocks for comparison with the authentic type."

Attention is concentrated mainly upon those strains which have shown particular promise in trials throughout the country, or, for special purposes or regions. Some reduction in the number of strains being handled by seed growers is, in itself, an aid to securing authenticity and greater purity of type.

"Field Approval" schemes have been applied to some 75,00o acres of wheat, barley and oats and more than 400 private individuals have been trained and examined at Cambridge as approved inspectors. The scheme is based on principle (3) and to some extent principles (I) and (2) ; it is supervised by the N.I.A.B.

The scheme marks a considerable advance on former methods of choosing cereal seed in the corn exchange by hand samples which cannot be identified in variety or judged for the presence of diseases or pernicious weeds.

Field Approval Schemes for Aberystwyth and Corstorphine herbage strains are based on principles (1), (2) and (3).

Comprehensive certification schemes for herbage seeds grown in the three counties of Lincolnshire, and in Wiltshire, Hampshire and Dorset, are based on all five of these principles. "Growing-on" tests have shown that the sealed bags contain seed of high varietal purity substantially free from pernicious weed seeds.

Vegetable seed stocks are now being developed under a co-operative scheme of the National Vegetable Research Station, the Seed Trade Association and the National Farmers' Union working in conjunction with the N.I.A.B.; this scheme depends for its value on principles ( 1 ), (4) and (5).

Economics must influence the choice of a suitable scheme. Crops such as broccoli and sprouts where the cost of seed normally constitutes only about 3 to 5 per cent. of the cost of growing the crop, justify a scheme which includes the sampling and sealing of packages and the growing of samples of seed.

Cereal seed which already represents about i 5 per cent. of the cost of growing the crop owing to the much slower rate of reproduction cannot easily bear the cost of operating principles (2), (4) and (5). But 'stock seed of cereals direct from the plant breeding stations multiplied at the N.I.A.B. and by the Welsh Seed Growers' Associations merits the application of the full range of principles ( $I$ ) to (5) so that the highest quality seed may be obtained for further multiplication.

A practical difficulty of seed certification schemes with vegetable seeds is that these are sold mainly in small packets and the seedsmen must be able to divide the original sealed bags. For the protection of all parties concerned the Swedish system of spraying certified seed with a substance which can be identified has 
much to commend it. A similar problem arises in the case of herbage seeds which are normally portioned out so that they may be mixed with other species in a form ready for sowing.

To meet, adequately, the need for bigger and more consistent yields of food crops it is essential to have a very clear understanding of the principles which influence the reproduction of improved stocks, an objective and experimental approach to the problem and the fullest utilisation of trained personnel at all stages of production.

\section{REFERENCES}

GREGOR, J. W., AND HORNE, F. R. I 935. Genecology and its agricultural significance. Agric. Progress, 12, 89-98.

HAWKINs, R. P. I 95I. A survey of commercial samples of herbage strains, I949-5I. Fourn. N.I.A.B., 6 ( $\mathrm{I})$, 49-54.

NORTH, G., AND sQuibis, F. L. Report on survey of vegetable stocks. N.I.A.B. Seed Prod. Com. Rep., no. 193 .

NORTH, G. 1952. Vegetative propagation of cabbage and allied vegetables. Emp. Fourn. Exp. Agric., 2o, 43-46.

H.M. Stationery Office Report : Seeds.

\section{BREEDING FOR YIELD IN THE CEREALS}

\section{R. N. H. WHITEHOUSE}

Plant Breeding Institute, Cambridge

There are two distinct methods of breeding for yield which Frankel describes as "overcoming limiting factors" and "assembling productivity genes." Examples of the former are breeding for disease and frost resistance. These methods are generally straightforward since the breeder has visible characters on which to select. The second method is more difficult, since advances may not become apparent until the selections have been tested for some years. The breeding systems in common use in hybrid cereal populations are based on two methods, neither of which is well suited for the study of quantitative characters. In the Pedigree Method about 95 per cent. of the plants in the segregating generations are thrown away each year, purely on eye judgment. In the Population Method about 95 per cent. of the seed is discarded each year purely at random. Natural selection favours those lines capable of most rapid multiplication under conditions of competition. In both methods high yielding lines may be discarded because there is no way of recognising them.

Trials of unselected crosses. - The Population Method may be modified by growing the early generations of unselected crosses in trial for yield comparisons either of different crosses or of different generations of the same cross. The early generations normally show heterosis; their yields sometimes exceeding that of the mid-parent by as much as 30 per cent. The amount of this excess may indicate the number of yield genes and, therefore, the possibility of selecting high yielding pure lines. Provided that no selection has occurred, the amount of this excess should be approximately proportional to the amount of heterozygosity remaining in the stock. Thus it will be halved at each generation so that hybrid and mid-parental yields will become equal when homozygosity is achieved. In trials of this type at Cambridge it is noticeable that winter wheat crosses have given much higher yields than spring wheat crosses relative to their respective parents. This may be due to segregation of the latter into early and late maturing types followed by natural selection against the late plants. This would invalidate the method since the absence of selection is an essential condition.

Trials of $F_{2}$ progenies.-The Pedigree Method may be modified by limiting selection to the $F_{2}$ and $F_{3}$ generations and then growing the progenies of selected $F_{3}$ plants in trial in $\mathrm{F}_{4}$ and later generations. Finally, single plant selections must be made within the high yielding progenies, as it has been shown that these contain more 
and better high yielding lines. The weakness of the method lies in the small number of progenies which can be adequately tested, although the use of cubic lattice designs may help. It is most applicable where $F_{2}$ and $F_{3}$ selection can be very intense thus reducing the number of progenies to be tested.

Analysis of single plants. - The yielding ability of a wheat variety is the product of the average values of grain weight and numbers of grains/spikelet, spikelets/ear, ears/plant and plants/unit area. Varieties owe their yield to different combinations of these five characters. In a hybrid population yielding ability can be estimated by measuring these characters and calculating a discriminant function in which each character is weighted arcording to the contribution it makes to yield. Then by applying these coefficients to the original single plants each can be assigned a score representing its yielding ability. A disadvantage of this method is the long time required to make the measurements and calculations. In analyses of spring wheats made at Cambridge, one $F_{2}$ showed a ro per cent. increase in number of spikelets per ear compared with the mid-parent. Presumably, if the other characters had also shown increased values, the possibility of selecting a high yielding line would be greater. Thus crossing two varieties owing their yield to a high expression of different characters may be more productive than merely crossing the highest yielding varieties.

Small scale yield trials. Yield differences of the order of 5 per cent. are frequently not significant even in field-scale trials. Breeders' trials, especially in early generations, are likely to be limited in size by the amount of seed available. It is, therefore, important to consider how this seed may best be used. A dibbed trial with spaced plants is the most economical way of using seed, but the effects of varying seed rate are still obscure. A comparison of two $6 \times 6$ Latin Square trials of barley, one drilled and the other dibbed showed that the drilled trial had a higher standard error, and also that the range of varietal yields was much greater. This more than compensated for the higher standard error with the result that the drilled trial was significant, whereas the dibbed one was not. The order of magnitude of the varietal yields was, however, virtually the same for the two trials. Other evidence suggests that the order of yields is sometimes inverted when changing the method of sowing. It seems possible, therefore, that the dibbed trial, which is essential if individual plants are to be studied, may give a wrong estimate of yield. This subject is now being investigated further at Cambridge.

\section{VARIETY TESTING}

\section{J. C. HAIGH}

National Vegetable Research Station, Wellesbourne

The subject of variety testing has been discussed at two previous conferences (1948 and 1949) and on the last occasion it was recommended that a small Committee be set up by the A.R.C. to consider the question in all its aspects. On this occasion it is possible in the time available to introduce only one point, and the suggestion is made that there is need for facilities for the plant breeder to test and select from breeding material in its early stages, while it is still variable, so that advantage can be taken of the reaction of heterozygous material to a wide range of conditions throughout the country. The testing of varieties or strains considered by the breeder to be highly promising is already well catered for by the N.I.A.B. and its chain of substations, but by the time the material reaches the trial plots of the N.I.A.B. it is a potential new variety. It is not generally possible to select at one centre for all climates and soils, and the wider testing, at an earlier stage, of moreheterozygous material may well lead to the ultimate selection of more than one variety. Two objections may be raised at once.

(a) that far too much work and organisation would be involved. It is suggested that trials of this kind over only a few years would indicate in which areas there were radical differences of environment which called for special 
attention and the number of trial areas could thereafter be reduced; and that in these exploratory stages, it should not be essential to have to establish new stations for the purpose-use could probably be made of existing facilities; or alternatively that a modest start could be made with existing facilities and the idea extended when it had proved its usefulness.

(b) that there are already too many varieties. Paradoxical as it may seem, a method such as is now suggested may well lead to a reduction in the number of varieties in use, since the intending grower could use a variety bred for his area instead of trying a random sample of the hundreds now on the market in the hope of finding one to suit his conditions.

The method used in the Commonwealth should be applicable, whereby hybrid material was sent out in early stages $\left(F_{2}\right.$ onwards) for small-scale trials and selection ; the field work was done by the man on the spot, but selection done by the breeder at HQ who worked with that particular crop or group of crops and who travelled around during breeding season. The N.V.R.S. have been offered facilities at the N.A.A.S. Experimental Horticulture Station, which it is proposed to use for the testing of this more-variable breeding material ; these stations are yet few; but it is proposed to begin in the hope that it will later be possible to expand. The testing of potential new varieties will continue to be done by the N.I.A.B.

\title{
NEW TECHNIQUES IN PLANT BREEDING
}

\author{
W. J. C. LAWRENCE \\ John Innes Horticultural Institution, Bayfordbury
}

Recently a variety of new aids to plant breeding have been developed which will make for better control, greater ease and speedier results.

The supplementary artificial illumination of seedlings is an example. By its use the quality of seedling growth is greatly improved in winter time (OctoberMarch), the rate of development is accelerated and plants come into flower and fruit earlier, thus making possible the raising of one or more generations per year. Artificial light can also be used to advance or retard the time of flowering in many species, a photoperiodic effect which is additional to that mentioned above for seedlings. The use of artificial light for photosynthetic and photoperiodic control is in its infancy, but clearly it provides a powerful tool for the plant breeder.

Temperature control is another promising aid. Already temperature and light control have been used to secure the flowering of biennial plants, such as beet and onions, in the first year, also for the selection of male plants in asparagus.

On the mechanical side there are a number of new aids. First, there is the electric "bee" for rapid and efficient pollination and the collection of pollen. Next, liquid air seems to offer considerable scope in the storage of pollen. Thirdly, use is made in Holland of certain wild queen bumble bees for the pollination of brassicas in insect-proof cabinets. These bees have diseased sexual organs (the result of nematode infestation) and consequently do not attempt to "home". They are caught by trained observers who identify them by their erratic flight. Much tedious work could be avoided by using such bees, especially where the flowers are small and difficult to manipulate.

Another aid developed in Holland is the "Dutch Light" structure, consisting of frame lights fixed to a metal or timber framework. This structure provides at small cost protection from wind and rain and can be readily adapted to provide controlled air and soil temperatures together with photoperiodic light control. The mobile glasshouse running on rails is another aid which deserves the attention of the breeder, especially for the maturing of crops and seed. Unfortunately almost all of these aids are only to be seen abroad, and one wonders if the camel-hair brush and forceps have not already become the insignia of the British plant breeder. 